\title{
Histopathological and Clinical Analysis of Variants in Cervical Lesion at Bhuj, Kutch, Gujarat
}

\author{
Jigna Upadhyay and Mitsu Vaishnav*
}

Department of Pathology, Gujarat Adani Institute of Medical Science, Bhuj, Kutch, Gujarat(India)

\section{ABSTRACT}

Background: Aim of the study was to know various histopathological variants in cervical lesion, its incidence with respect to age in Bhuj city of Gujarat.

Materials \& Methods: A total of 618 cases of cervical lesions were analysed prospectively in a period of 2 years to assess various pattern of cervical lesion. Cases were studied in detail about history, clinical examination and other findings.

Results: Of the total 618 cases, $516(83.50 \%)$ were non neoplastic all of which were inflammatory and 102(16.5\%) were neoplastic of which cervical malignancies, benign lesions and cervical intraepithelial neoplasia (CIN) constituted 80(12.94\%), 12(1.94\%) and 10(1.62\%) respectively. Amongst inflammatory lesions, the commonest lesion was chronic nonspecific cervicitis $428(82.95 \%)$ followed by papillary endocervicitis $88(17.05 \%)$. The associated changes of chronic nonspecific cervicitis were nabothian cyst (11.92\%), squamous metaplasia $(11.68 \%)$, and koilocytic change (22.43\%). Inflammatory lesions were commonly found in the sexually active period of women i.e. 31 50 years with a peak incidence in the age group of 31-40 years. Cervical malignancies were common in the age group of 40-60 years and presented most commonly with bleeding per vagina. CIN was most common in the age group of 41-50 years with CINII as the predominant grade having white discharge as the most common symptom.

Conclusion: Non-neoplastic were the commonest lesions of the cervix. Women in the older age group with bleeding per vagina should be suspected for cervical malignancy and should be examined for the same

Keywords: Neoplasia, Malignancy, Metaplasia,Vagina

\section{Introduction}

Cervix is the lower part of uterus which connects this organ to the vagina through the endocervical canal. ${ }^{[1]}$ The cervix is both a sentinel for potentially serious upper genital tract infections and a target for viruses and other carcinogens which may lead to invasive carcinoma of the uterine cervix. ${ }^{[2]}$ Invasive squamous cell carcinoma of the cervix is still the most common malignant tumor of the female genital tract in most countries and the most frequent neoplasm among women in many of them.

Smith and Pemberton (1934) reported a relationship between CIS (Carcinoma in situ) and invasive cancer when they found that the changes described as CIS by Broders were present in a retrospective review of biopsies from patients who subsequently developed invasive cancer. This combination of histologic observations and retrospective clinical analysis led to the concept that invasive squamous cell carcinoma develops from precursor lesions that can be identified by the pathologist. ${ }^{[3]}$

Realizing its importance, through this study we hope to get a better understanding of the whole spectrum of lesions affecting the uterine cervix.

\section{Material and Method}

Present study was performed at Department of Pathology, Gujarat Adani Institute of Medical Science, Bhuj, Kutch, Gujarat. On approval from ethical committee, in our prospective study, 618 cases were analyzed for a period of 2 years during September 2013 to August 2015 in pathology department at SRTR Ambejogai. It includes specimens and reference material submitted to department of pathology in the form of biopsy specimens and hysterectomy specimens. Data was obtained from hospital records and specimens sent from various departments. All the lesions of cervix involving ectocervix and endocervix were included. Various lesions arising from the uterus, vulva, vagina and parametrium were excluded. Also the lesions arising from neighbouring organs extending to the cervical canal but not involving the cervical tissue were excluded. Every patient was evaluated by using a preformed proforma.

Gross examination was done and features such as size, consistency, external appearance and appearance of cut surface were noted. The specimens were allowed to fix in $10 \%$ formalin for $24-48$ hours. The sections were dehydrated in alcohol, cleared in xylol and embedded in paraffin wax to prepare the paraffin blocks. Multiple thin sections of 
$4-5$ microns in thickness were cut. Multiple blocks from different areas of lesion were studied in each case. For histopathological study, the paraffin embedded sections were stained by Hematoxylin and Eosin (H \& E) stain.

\section{Results}

The total number of female genital tract lesions was 2020, out of which cervical lesions formed a major part constituting 618 lesions. In the present study hysterectomy was the most common type i.e. 512 of specimens received for histopathological examination followed by the specimens from cervical punch biopsy 86 , polypectomy 11 and Fothergills operation 9.

Among the total 618 lesions 516(83.50\%) were nonneoplastic and $102(16.50 \%)$ were neoplastic. All the nonneoplastic lesions 516(83.5\%) were found inflammatory type. Among the total $102(16.5 \%)$ neoplastic lesions, most common was the malignant lesions $80(12.94 \%$ ) followed by benign lesions $12(1.94 \%)$ \& CIN as $10(1.62 \%)$. (Table 1)

Chronic nonspecific cervicitis was the commonest inflammatory lesion found in $428(82.95 \%)$ cases followed by papillary endocervicitis found in $88(17.05 \%)$ cases. Inflammatory lesions both chronic nonspecific cervicitis and papillary endocervicitis were commonly found in the sexually active period of women i.e. 31-50 years with a peak incidence in the age group of 31-40 years. (Figure 1)

Chronic nonspecific cervicitis (CNSC) was associated with other histological changes like koilocytosis 96(22.43\%), nabothian cyst 51(11.92\%), and squamous metaplasia $50(11.68 \%)$. Endocervical polyp was the most common benign lesion in the age group of $31-40$ years. The occurrence of cervical intraepithelial neoplasia in this study was 10 out of $618(1.62 \%)$ cases. The cervical intraepithelial neoplasia was mainly of squamous cell origin. There were no cases of cervical intraepithelial glandular neoplasia found in this study. CIN was most common in the age group of 41-50 (50\%) years with CINII as the predominant grade.

Out of 10 cases of CIN, $6(60.0 \%)$ cases presented with white discharge, $4(40.0 \%)$ had mass per vaginum, $3(30.0 \%)$ had pain in abdomen, $1(10.0 \%)$ had post- menopausal bleeding and $1(10.0 \%)$ case had complaint of post coital bleeding. Cervical malignancies formed a major part constituting $80(78.44 \%$ ) out of 102 malignancies in the female genital tract. Squamous cell carcinoma was the predominant histologic type of cervical malignancy constituting 76(95\%) cases. Cases of adenocarcinoma and a case of adenosquamous carcinoma were also encountered in this study which accounted for $3(3.75 \%)$ cases and $1(1.25 \%)$ case respectively.

In the present study, it was evident that the incidence of invasive carcinoma was most common in the age group of 40-60 years followed by age group greater than 60 years. It was observed that with an increase in age there was an increase in the number of malignancies.

In the present study squamous cell carcinoma was classified according to Broder's grading system into well, moderately and poorly differentiated at the time of initial diagnosis and constituting cases as $9(11.84 \%), 54(71.05 \%)$ and $13(17.11 \%)$ respectively. Squamous cell carcinoma most commonly presented with bleeding per vagina and post coital bleeding. Most of the patients with adenocarcinoma presented with bleeding per vagina.

\section{Discussion}

In present study, cervical lesions constitute $30.18 \%$ of total female genital tract lesions. This finding match with that found in study by Poste P et al (32.31\%). ${ }^{[4]}$ In the present study hysterectomy $(82.85 \%)$ was the most common type of specimen received for histopathological examination followed by cervical biopsy (13.92\%) specimens. This was in accordance with the study done by Pallipady A et al ${ }^{[5]}$ Overall non-neoplastic lesions $(83.5 \%)$ were more than the neoplastic. This finding was in keeping with previous reports by Saravanan $\mathrm{S}$ et al. (79.7\%). ${ }^{[6]}$ In this study, chronic non-specific cervicitis accounted for $82.95 \%$ of all cervicitis. This finding was similar to previous work done by Omoniyi-Esan et al ${ }^{[7]}$ where chronic non-specific cervicitis accounted for $82 \%$ of all non-neoplastic lesions. Maximum number of cases was found in 31-50 years of age group present study correlated well with the study of Omoniyi-Esan et al.

Table 1: Histopathological distribution of cervical lesions.

\begin{tabular}{|c|c|}
\hline Cervical lesions & Number of Cases \\
\hline Inflammatory & 516 \\
\hline Neoplastic & 102 \\
\hline Benign & 12 \\
\hline CIN & 10 \\
\hline Malignant & 80 \\
\hline Total & $\mathbf{6 8 0}$ \\
\hline
\end{tabular}




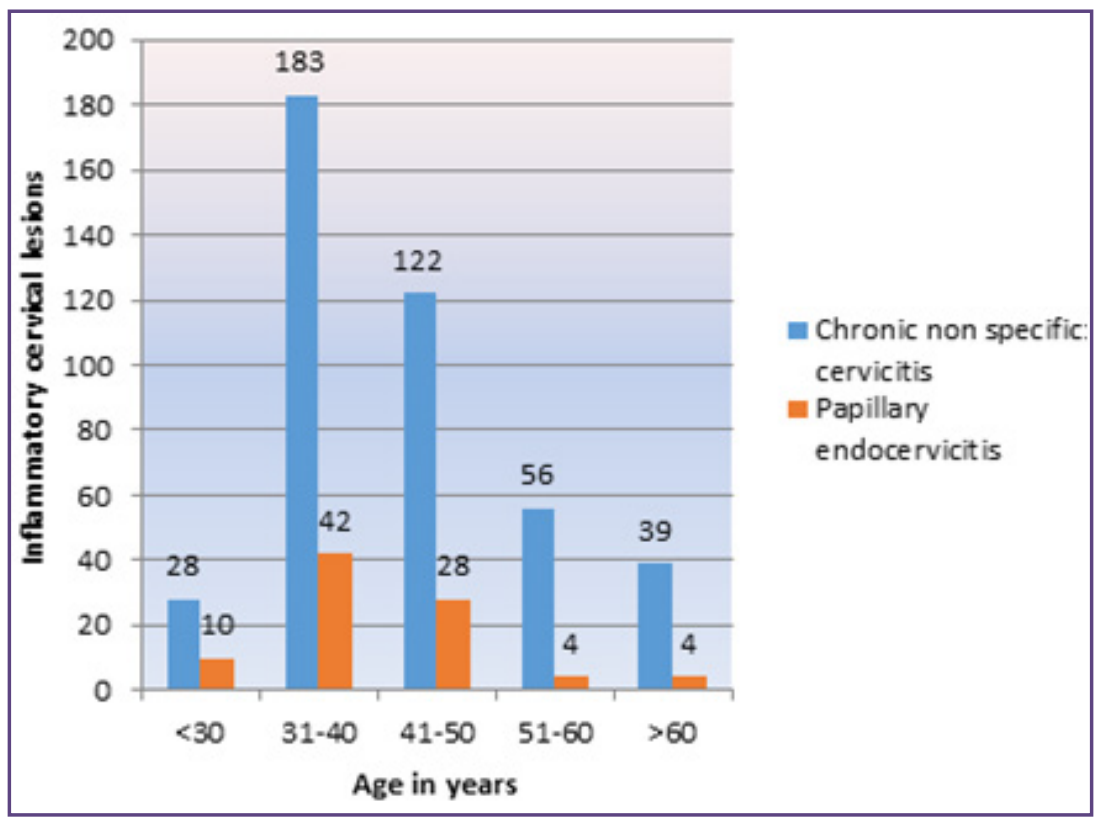

Fig. 1: Age wise distribution of cervical inflammatory lesions.

Chronic non-specific cervicitis was associated with other histological changes like squamous metaplasia, koilocytosis and nabothian cyst. Chronic nonspecific cervicitis with nabothian cyst was found in 51(11.92\%) cases. The results found in this study were slightly higher than those found in the study conducted by Jyothi et al. ${ }^{[8]}$ Chronic nonspecific cervicitis with squamous metaplasia was found in 50(11.68\%) cases. The results found in this study were slightly higher than the study conducted by Jyothi et al. and Poste P et al. Chronic nonspecific cervicitis with koilocytic change was found in $96(22.43 \%)$ cases. This finding was also found slightly higher than that found in the study conducted by Jyothi et al. This could be due to differences in sample size and health awareness amongst the study population.

Endocervical polyps were most commonly seen in the age group of 31-40 years in the present study. Poste $\mathrm{P}$ et al. documented endocervical polyps in the age group of 41-50 years. This variation may be due to small sample size.

Occurrence of CIN was low (1.62\%) when compared to other studies. ${ }^{[9,10]} \mathrm{A}$ low incidence of CIN and high incidence of cervical malignancy seen in this study may be due to the reluctance on part of rural women to undergo physical examination and probable due to ignorance and lack of proper facilities. In the present study moderate dysplasia [CIN-II] made up the maximum number of dysplasia cases as in accordance with the study of Poste $\mathrm{P}$ et al. who found it as $49.01 \%$. Karim AJ et al ${ }^{[11]}$ documented highest number of CIN cases in the age group of 41-50 years. In the present study also maximum cases were noted in the age group of 41-50 years. In the present study white discharge was the most common complaint in the patients with CIN which was in accordance with Poste P et al.

In the present study cervical malignancy was noticeable in 80 cases and constituted $78.44 \%$ malignancies of female genital tract. This was a very significant finding.

In the present study cervical cancer accounted for $12.94 \%$ cases of all cervical lesions which was comparable to the study done by Saravanan S et al. ${ }^{[6]}$ and Sinha $\mathrm{P}$ et al. ${ }^{[12]}$ whereas it was less when compared to Jyothi et al. ${ }^{[8]}$

In the present study squamous cell carcinoma was the commonest of the invasive lesions encountered in this study, accounting for $95 \%$ of the total invasive carcinoma which was comparable with the study of Shruthi PS et al. ${ }^{[13]}$ and Oguntayo et al. ${ }^{[14]}$ Present study reported highest number of cases of squamous cell carcinomas in the age group of 40-60 years. Shruthi PS et al. and Jyothi et al. also found it as highest in the age group of 40-60 years. Kaarthigeyan ${ }^{[15]}$ in 2012 reported that the incidence rises in 30-34 years of age and peaks at 55-65 years, with a median age of 38 years. In the present study $54(71.05 \%)$ cases of squamous cell carcinoma were of the moderately differentiated type. This finding was in accordance with the study of Shruthi et al. who also found majority (55.90\%) of cases of squamous cell carcinoma of moderately differentiated type. In the present study most of the patients presented with bleeding per vagina which was similar to the finding of Ijaiya et al. ${ }^{[16]}$ 
In the present study 3 cases of adenocarcinoma were encountered. Two cases were of papillary adenocarcinoma and one case was of mucinous endocervical type which correlated with the study of Shruthi PS et al All three cases were seen in the age group of 51-60 years and presented with bleeding per vagina. Shruthi PS et al. documented age of adenocarcinoma from 40-60 years. Present study correlated well with the study of Shruthi et al.

\section{Conclusion}

Cervical malignancies formed a major part of the female genital tract malignancies constituting 78.43\%. Nonneoplastic were the commonest lesions of the cervix. Endocervical polyp was the most common benign cervical lesion. CINII was the predominant grade. Commonest cervical malignancy was squamous cell carcinoma, moderately differentiated being the commonest type. Inflammatory lesions were commonly found in the sexually active period of women. CIN was most common in the age group of 41-50 years and the most common associated symptom was white discharge. Cervical malignancies were common in the age group of 40-60 years and presented most commonly with bleeding per vagina. Hence women in the older age group with bleeding per vagina should be suspected for cervical malignancy and should be examined for the same.

\section{References}

1. Rosai J. Rosai and Ackerman's Surgical Pathology. 10th ed. India: Elsevier Inc.; 2011.p.1436-1460.

2. Ellenson HA, Pirog EC. The female genital tract. In: Kumar V, Abbas AK, Fausto N, Aster J, editors. Robbins and Cotran Pathological Basis of Diseases. 8th ed. Philadelphia: Saunders Elsevier; 2010. p. 1017-1024.

3. Singer A, Monaghan JM. Lower Genital Tract Pre-cancer Colposcopy Pathology and Treatment., 2nd ed. U.S.A: Blackwell Science; 2000. P. 1-11.

4. Poste P, Patil A, Andola SK. Incidence of Non-Neoplastic Cervical Pathologies Recorded at a Medical College. International Annals of Advanced Scientific Research 2015 Mar 19;2(2):006-017.
5. Pallipady A, Illanthody S, Vaidya R, Ahmed Z, Suvarna R, Metkar G. A clinico-morphological spectrum of the non-neoplastic lesions of the uterine cervix at AJ Hospital, Mangalore. Journal of Clinical and Diagnostic Research 2011;5:546-550.

6. Saravanan S, Arnold J, Arul P. Histomorphological Spectrum of lesions of the cervix, a Retrospective Study in a Tertiary Care Hospital. J Evol Med Dent Sci 2015;4(59):10326-10329.

7. Omoniyi-Esan OG, Osasan SA, Ojo OS. Non-neoplastic diseases of the cervix in Nigerians: A histopathological study. African health sciences 2006 Sep 25;6(2):76-80.

8. Jyothi V, Manoja V, Sridhar K. A clinicopathological study on cervix. J Evol Med Dent Sci 2015;4(13):2120-2126.

9. Poste P, Patil A, Andola SK. Incidence of neoplastic cervical pathologies recorded at a medical College. International Annals of Advanced Scientific Research 2015 Apr 4;2(2):018-035.

10. Jain A, Rachna J, Iqbal, Koteeswaran G, Dhannanjay S, Kamble T. Histopathological study of tumours of cervix. Advances in Cancer Research \& Therapy 2014;1(2):1-8

11. Karim AJ, Al-Naggar RA, Poil San MM. Histopathological findings for cervical lesions in Malaysian women. Asian Pacific Journal of Cancer Prevention 2009 Jan 1;10:1159-1162.

12. Sinha P, Rekha PR, Subramaniam PM, Konapur PG, Thamilselvi R, Jyothi BL. A clinicomorphological study of carcinoma cervix. National Journal Of Basic Medical Sciences 2011;2(1):4-7.

13. Shruthi PS, Kalyani R, Kai LJ, Narayanaswamy. Clinicopathological correlation of cervical carcinoma: A tertiary hospital based study. Asian Pac J Cancer Prev 2014;15(4):1671-1674.

14. Oguntayo OA, Zayyan M, Kolawole AO, Adewuyi SA, Ismail H, Koledade K. Cancer of the cervix in Zaria, Northern Nigeria E-cancer medical science. 2011 Jan 1;5:219.

15. Kaarthigeyan K. Cervical cancer in India and HPV vaccination. Indian J Med Paediatr Oncol. 2012 JanMar;33(1):7-12.

16. Ijaiya MA, Aboyeji AP, Olatinwo AW, Buhari MO. Clinicopathological presentation of primary cervical cancer seen in Ilorin, Nigeria. Nigerian Journal of Surgical Research 2002;4(3):89-93.

*Corresponding author:

Mitsu Vaishnav, Department of Pathology, Gujarat Adani Institute of Medical Science, Bhuj, Kutch, Gujarat (India)

Email: researchguide86@gmail.com

Financial or other Competing Interests: None. 